\title{
Correction to: Metacytofilin, a novel immunomodulator produced by Metarhizium sp. TA2759
}

\author{
Masatomi lijima ${ }^{1} \cdot$ Tohru Masuda $^{1} \cdot$ Hikaru Nakamura $^{2} \cdot$ Hiroshi Naganawa $^{2} \cdot$ Shogo Kurasawa ${ }^{2} \cdot$ Yoshiro Okami $^{2} \cdot$ \\ Masaaki Ishizuka' ${ }^{1}$ Tomio Takeuchi ${ }^{1,2} \cdot$ Yoichi litaka $^{3}$
}

Published online: 27 September 2018

(C) The Author(s) under exclusive licence to the Japan Antibiotics Research Association 2018

Correction to: The Journal of Antibiotics (1992) 45, 1553-1556. https://doi.org/10.7164/antibiotics.45.1553

The authors of the above article misjudged the structure determination of MCF (metacytofilin). Our recent analyses using X-ray crystallography and NMR techniques revealed the correct structure as shown in Figs. 1, 2, and 3. The structure of MCF was identified with diatretol [1].

Single-crystal X-ray data were collected on a Rigaku RAXIS RAPID diffractometer using filtered $\mathrm{Cu}-\mathrm{Ka}$ radiation. The crystal data are: empirical formula: $\mathrm{C}_{16} \mathrm{H}_{22} \mathrm{~N}_{2} \mathrm{O}_{4}, \mathrm{FW}$ 306.36, crystal color: colorless, habit: platelet, crystal dimensions: $0.300 \times 0.200 \times 0.030 \mathrm{~mm}$, crystal system: monoclinic, lattice type: primitive, lattice parameters: $a=$ 6.06079 (14) $\AA, b=17.1982$ (4) $\AA, c=9.1651$ (2) $\AA, \beta=$ $108.523(8)^{\circ}, V=905.83(6) \AA^{3}$, space group: $\mathrm{P} 2{ }_{1}, Z$ value: 2, $D_{\text {calc }}: 1.123 \mathrm{~g} / \mathrm{cm}^{3}, F_{000}: 328.00, \mu(\mathrm{CuKa}): 6.671 \mathrm{~cm}^{-1}$. The structure was solved by direct methods [2] and expanded using Fourier techniques. The non-hydrogen

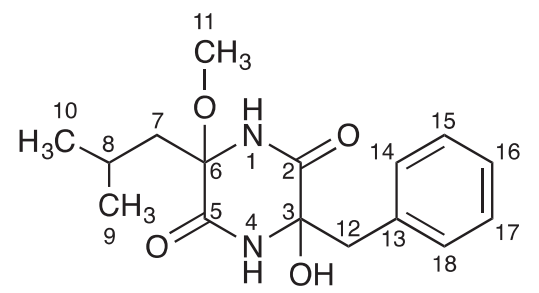

Fig. 1 Structure of metacytofilin (MCF)

Masatomi Iijima

iijimam@bikaken.or.jp

Institute of Microbial Chemistry (BIKAKEN), Shizuoka, Japan

2 Institute of Microbial Chemistry (BIKAKEN), Tokyo, Japan

3 Laboratory of Biophysics, Faculty of Pharmaceutical Sciences, Teikyo University, Tokyo, Japan atoms were refined anisotropically. Hydrogen atoms were refined using the riding model. The final cycle of full-matrix least-squares refinement [3] on F2 was based on 3233 observed reflections and 199 variable parameters and converged (largest parameter shift was 0.00 times its esd) with unweighted and weighted agreement factors of:

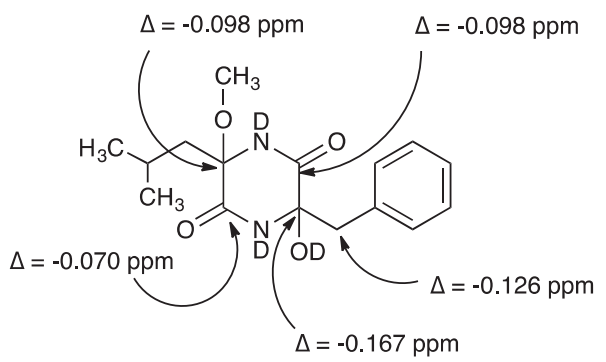

Fig. 2 Deuterium isotope effects on ${ }^{13} \mathrm{C}$ chemical shifts of $\mathrm{MCF}$ observed in $\mathrm{CD}_{3} \mathrm{OD}$ and $\mathrm{CD}_{3} \mathrm{OH}$ solutions

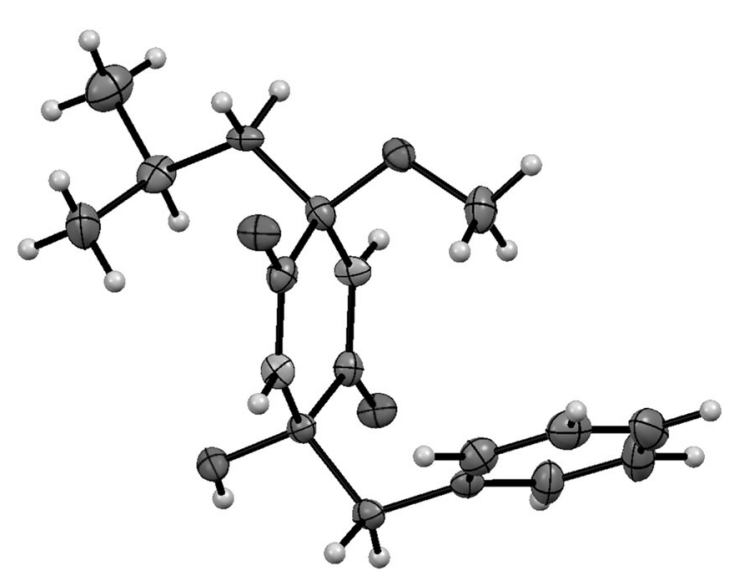

Fig. 3 Molecular structure of MCF using SHELXT 
$R_{1}=S|| \mathrm{Fo}|-| \mathrm{Fc} \| / S|\mathrm{Fo}|=0.0576$,

$w R_{2}=\left[S\left(w\left(\mathrm{Fo}^{2}-\mathrm{Fc}^{2}\right)^{2}\right) / S w\left(\mathrm{Fo}^{2}\right)^{2}\right]^{1 / 2}=0.1455$.

\section{Compliance with ethical standards}

Conflict of interest The authors declare that they have no conflict of interest.

\section{References}

1. Arnone A, et al. Secondary mould metabolites, LII. structure elucidation of diatretol - a new diketopiperazine metabolite from the fungus Clitocybe diatreta. Liebigs Ann. 1996;1996:1875-77.

2. Sheldrick GM. SHELXT version 2014/5. Acta Cryst. 2014;A70: C1437.

3. Least squares function minimized: (SHELXL version 2014/7) $S w$ $\left(\mathrm{Fo}^{2}-\mathrm{Fc}^{2}\right)^{2}$ where $w=$ least squares weights. 